\title{
Extension and Credit in an Integrated Rural Development Project in Sierra Leone
}

\section{Alec Baird}

This paper summarises the findings of research undertaken in 1974 on the organisation and management of the Integrated Agricultural Development Project in the Eastern and Southern Provinces of Sierra Leone, a World Bank assisted project. Structural aspects of the project, in terms of organisation and management, had been largely ignored during the planning process, and the research was designed to investigate the implications of this.

Attention to project structure is important for any large project, programme or package in which success depends on the interaction of, and goodwill between, more than one component. It is especially important with regard to integrated activities, where the attempt to bring together a number of components under one project management presents special problems of organisation. By identifying problems of operation, co-ordination and control at the outset, many of these problems can either be avoided or allowed for in the organisation, so that the chances of project failure are considerably reduced.

Integrated projects differ greatly in their consti- tuent components; in the way that they are administratively integrated; and in their environments. It is therefore unlikely that the optimum organisation in one situation will be transferable to another. It is possible, however, by using the knowledge and experience of organisation theory, to approach the problems in a logical and systematic way.

The theoretical approach used for the research was the organisation design approach (Hutton 1972; Clark 1972). The analytical method for applying this approach is based on systems theory (Miller and Rice 1967). Briefly, systems theory differentiates between 'operating activities', which are concerned directly with the system's 'primary task', and 'regulation' and 'maintenance' activities, which, respectively, control the system and provide the necessary resources for the operating activities. Regulation has two parts: 'boundary control' which regulates transactions and relations between the system and its environment; and 'monitoring activities' which regulate the internal workings of the system. The primary task is a heuristic concept; it is quite possible for a system to have more than one task, or to have a hierarchy of tasks. Any given primary task can be analysed in terms of its flow of activities, the logical sequence of activities needed to achieve the task. Comparing different organisation designs for different interpretations of a system's primary task provides an analytic method of identifying their respective strengths and weaknesses.

\section{The project}

The two major primary tasks of the project were extension and credit. The crops concerned were swamp rice, cocoa, and oil palm, the latter having a semi-independent organisation based on a plantation with outgrowers, although still responsible to the project manager. The Agricultural Extension Officers were to be assisted in the solution of technical problems by a Technical Services Unit made up of a Rice/Cocoa Officer concerned with fertilisers, pesticides and disease, and a Land Planning Officer who assisted with the planning and construction of irrigation for swamp rice. There was also a training component in the project.

The structure of the project and the creation of small functional units were a direct result of the Project Manager's view of an integrated project. $\mathrm{He}$ felt that, as an integrated project is short-term and complex in terms of the co-ordination of activities required, the essential organisational requirement was strong centralisation. This was epitomised by a span of control of ten: accounts, internal audit, administration, training, credit, land planning, rice/cocoa technical services, agricultural extension, oil palm, and the project agent in Freetown. There was little delegation of authority, and the units formed were small, somewhat isolated, and specialised. In this way, the Project Manager felt that the direct control necessary in this type of project for effective coordination and achievement of a common goal could be exerted. Essentially, the Project Manager was the ultimate control and exercised it with a large amount of personal contact.

This organisation of project activities resulted from the emphasis placed by the project's policy on extension, as stated in the 1973 Annual Report. ${ }^{1}$

1 Integrated Agricultural Development Project for the Eastern and Southern Provinces, 1974, Annual Report 1973, International Bank for Reconstruction and Development. 
The catchphrase 'every farmer counts' was elaborated as follows:

Such a policy endeavours to reduce special effort on a few favoured farmers and to provide a full extension service available to all. However, the policy also implies a high cost of making these services available to farmers. This policy can be justified, providing the extension effort is fully successful.

The emphasis on either 'credit' or 'extension' can be seen, in its most exaggerated form, as a choice between assisting only those farmers who are creditworthy and economically viable, as against assisting all farmers in the project area by extension activities. The options are usually not as polarised as those stated above, and many compromises are possible; nevertheless, they epitomise the two opposing views of the project's activities.

The Project Manager considered that extension success was vital to the success of the project, and placed the emphasis on this aspect of project activities, rather than on the credit operation. He appreciated, however, that a balance must bo achieved between the two and that repayments of credit had to be made, although without making the operation too profitable.
Credit was regarded as a useful tool for providing inputs with which the extension effort could function effectively. It was the Project Manager's intention that credit and extension should work parallel to each other. The extension service should be 'the farmer's friend', whilst the credit section should be the 'policeman'. In this climate, the Land Planning Officer was encouraged to consider the whole of the project area's 4,000 square miles for possible development. The 'extension' criteria for accepting a farmer were his willingness and ability to comprehend and utilise project assistance. The situation applied particularly to swamp rice, both as the largest project crop and the most diffused geographically.

\section{The project organisation of activities}

Three major studies had been undertaken in the planning process for the project: a feasibility study conducted by the Commonwealth Development Corporation; a World Bank Project Preparation Report; and the final World Bank 'Grey Cover' Document. The three had proposed significantly different project organisations. The Project Preparation Report, for example, had recommended a regional approach to the field operations with three Zonal Managers in charge of all field operations, cocoa, rice and timber

Figure 1

Observed flow of activities in a IRDP in Sierra Leone

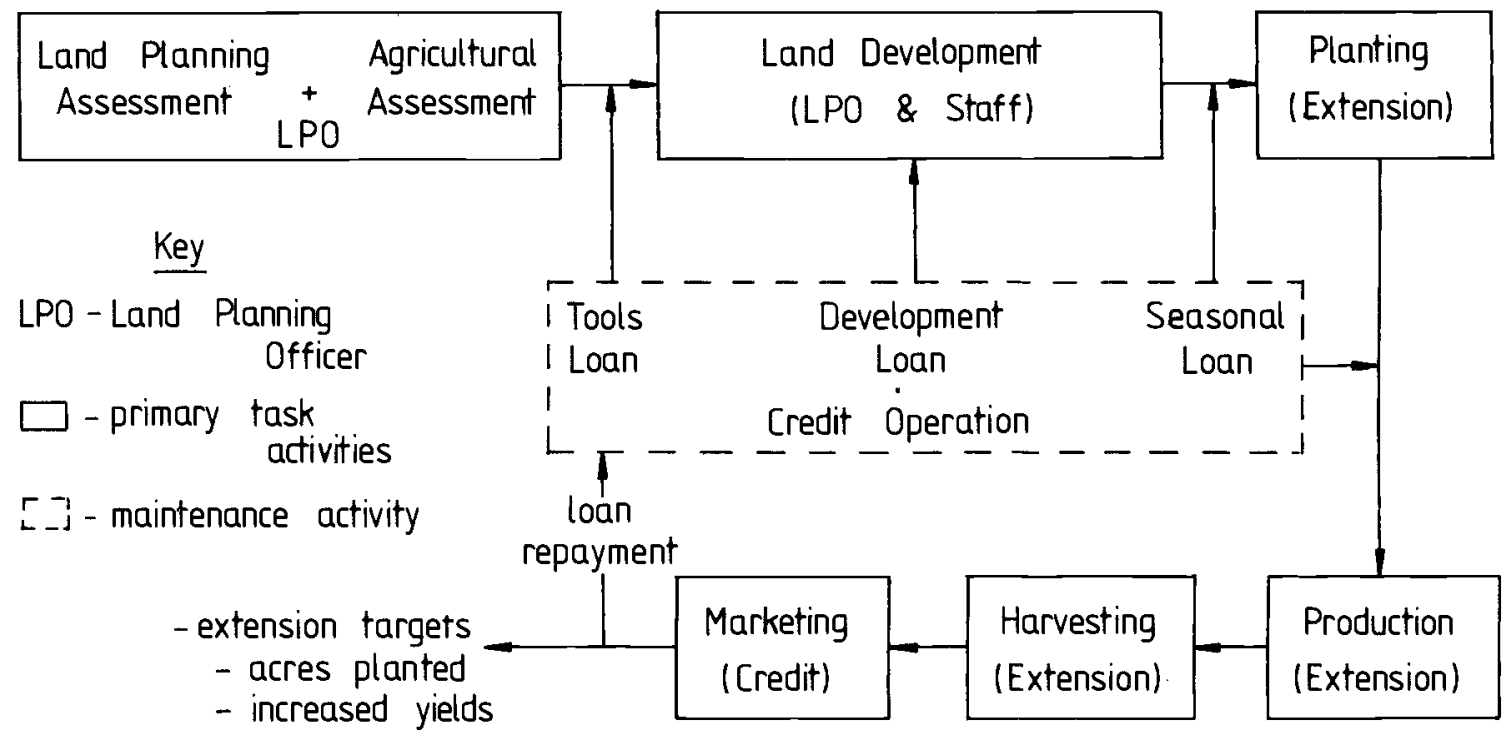


(later changed to oil palm), extension work plus credit. Assistant Managers would supervise resident instructors in agricultural and credit operations.

In the project, eventually definied by the 'Grey Cover' Document, field operations were still to be managed on an area basis, but with one very important change. The four regions were now purely agricultural, managed by three Agricultural Officers and the Plantation Manager, who were responsible for all extension work in their areas. Credit did not appear as part of the primary task in the flow of activities, but as a maintenance function (Figure 1). Whereas the first two proposals to emerge from the planning process considered the integration of project activities at the field level to be essential, to the extent of making Zonal Managers responsible for all project operations, the 'Grey Cover' document actually proposed splitting the two major project activities and removing one from regional control. The integration of credit and extension could only then occur at project management level. 'Credit' supported 'extension' and had no deterministic role of its own.

The processes for oil palm and cocoa were very similar to those for swamp rice, except that no separate function of land planning was required. Land preparation and the acceptance of farmers by the project was undertaken by the extension service, together with the technical assessment of the land. The output of the primary task system was the achievement of extension targets, as laid down in the 'Grey Cover' document, in terms of acres planted and the increase in yields.

The organisation of an integrated project is often made considerably more difficult by the fact that the various components interact with each other, rather than following a logical sequence. Thus, instead of

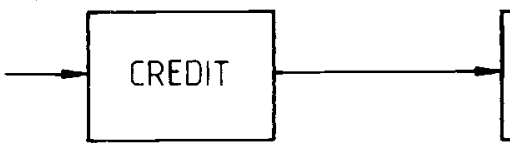

\section{EXTENSION}

Co-ordination of the different activities, their control, and the emphasis given to a particular type of activity, are crucial factors in the management of the project and the achievement of the project's primary task. There are, therefore, two aspects of organisation design which must be considered: the structure as shown by management boundaries and the relationships between the different activities contributing to the primary task system. There is a clear technological distinction between the processes of 'credit' and 'extension', where 'process' is defined as a connected sequence of actions or operations deliberately undertaken. What is not clear is the relationship between the two, or where the boundaries exist in their interaction with each other.

The main point to emerge from this indistinctness in the flow of activities is that the most important aspect of organisation is the management of the primary task system, involving co-ordination of the interaction of activities. Other aspects of organisation design are of secondary importance, and can, to some extent, be variously organised with little adverse effect on overall project effectiveness.

\section{Rationalising the organisation of activities}

In Figure 1 the emphasis on extension is illustrated by the continuous flow of extension activities and the periodic injection of credit inputs. Such a presentation illustrates that extension can be successful in its own right and that credit, far from being a necessary part of the flow, merely provides an added impetus to the process. In the situation where emphasis is placed on credit, however, the reverse is not true.

Credit has not been successful on its own: it depends heavily on a good extension service to supervise the application of credit inputs, as

as distinct and separate processes, a typical combination would be:

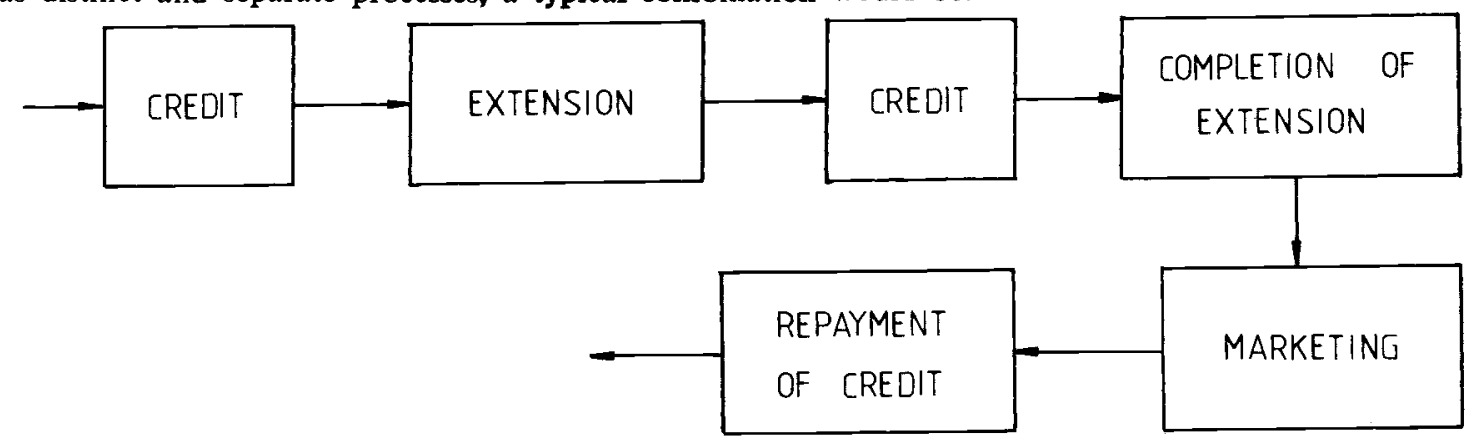


proved by the failure of previous credit schemes in Sierra Leone which did not have adequate extension services to support them. It is significant that the first project to provide adequate extension services in a specific area achieved almost 100 per cent return on credit in the first year of its operations. This cannot be attributed solely to good credit management: adequate supervision and motivation of the farmers were also involved. Without this supervision and motivation, the inputs are wasted, sold or inefficiently applied. Consequently, Figure 2 which illustrates the primary task with the emphasis on credit, or jointly on credit/extension, shows credit and extension as part of the same flow of activities. regulation mechanisms is of prime importance to the credit emphasis, and is the fundamental difference between the credit emphasis and the extension emphasis. The credit section would have a boundary control function in all transactions between the project and the farmers, so as to maintain strict supervision and ensure the successful establishment of a Revolving Credit Fund. Project operations would be extended only to those parts of the project area where repayment was considered probable. The success of project activities in establishing the Revolving Credit Fund would depend entirely on the percentage repayment of loans. Good judgement of farmers' profitability and the subsequent ability to control

\section{Figure 2 Flow of Activities giving Credit and Extension Equal Weight}

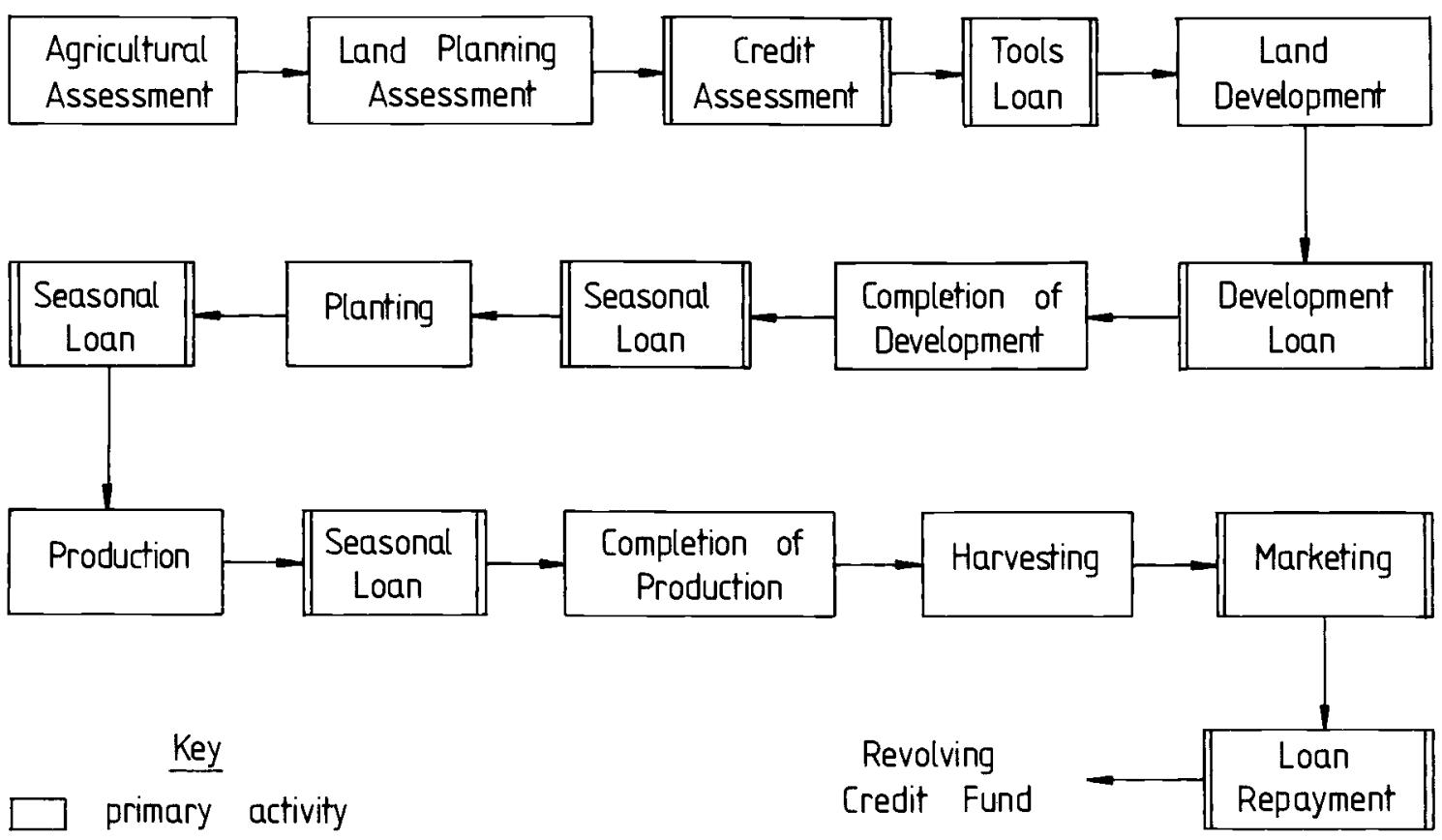

\section{$\square$ boundary control activity}

Three types of assessment are made during the flow of activities for rice: an agricultural assessment of individual swamps carried out by the Agricultural Officer; a land planning assessment of each swamp by the Land Planning Officer; and, finally, a credit assessment of each farmer by the Credit Manager. This final assessment, which was missing from the actual flow of activities, would have to carry the power of veto over the other assessments, if credit were to be the primary activity. Control of the decision-making and operations would be the main criteria influencing the location of project activities.

In every transaction with the farmers, the credit section would insert a control mechanism. So when, for example, the assessments were complete, the distribution of the tools loan would take place under the control of the credit section. When development work was complete, the credit section would evaluate the situation, with the advice of the extension service, and then control 
the distribution of seeds and fertiliser. The difference between Figure 1 and Figure 2 is that in Figure 1 the credit section has no control over its own actions. Credit controls should exist whereever there is a transaction between the project and the farmer.

An indication of where the project's emphasis lay between credit and extension is the role of the Land Planning Officer. In the organisation existing at the time of the research, he was a key figure in the policy of emphasising extension through his role in selecting and signing on farmers to the project. In an alternative design, and one which stresses credit, the Land Planning Officer would revert to a purely advisory role in the Technical Services Unit, without the power of decisionmaking except in his own field of technical competence.

Of the three possible points of emphasis, the most difficult to manage and the one requiring most consideration is the joint emphasis on both credit and extension. A working assumption can be made that the major problem is not only one of control, but one of balance: how to achieve the maximum extension effort, in terms of the number of farmers reached, acreages and yields; and the guaranteed return on credit necessary for establishing a Revolving Credit Fund capable of sustaining itself. A major problem was that the project's credit operation, aimed at small-holders, worked on low rates of interest in order to make credit feasible for small-holders. In doing so, it required a very large percentage to be repaid in order to break even. The credit section of the project worked on a 96 per cent minimum repayment. If, as was hoped, the Fund was to provide insurance against crop disasters, then an even higher percentage recovery was required. Such a situation left little room for manoeuvre and made some form of credit control a necessity. In fact, for a viable credit operation with the necessary assessments and controls, the flow of activities shown in Figure 2 was essential.

To give equal emphasis to extension and credit the project must have an organisation design that does not discriminate, as the 'Grey Cover' document did, in favour of extension. In addition it must be understood by all parties concerned that extension work will have to be limited, to some degree, by the requirements of credit.

\section{Omissions in the planning process}

If the decision to emphasize extension had been the stated policy of the project from the planning stage, there would be no need to consider alternative designs based on different emphases. There were, however, certain anomalies in the original emphasis. If a credit component exists as part of a project, it must be there for one of two reasons: either it is to establish a successful credit operation capable of self-regeneration, or it is to support other activities, such as extension, through subsidised financing. The latter would be with the expectation of some losses, in which case it would not be self-generating, but would be a short-term input to facilitate the establishment of other activities. It would seem that the choice between these alternatives is fundamental both to project planning and to the project's operating policy. At neither stage of the project's development, however, was such a choice made apparent. The credit section was aiming at the establishment of a Revolving Credit Fund, by ensuring the maximum percentage repayment possible. This attitude, together with the credit control measures necessary to achieve maximum repayment, often conflicted with the extension emphasis, which required a credit subsidy aproach. The attitude of the credit section was strengthened through being a selfcontained unit, responsible directly to the Project Manager, and with no formal relationships with the extension section.

If the project's primary task has been spelt out in the 'Grey Cover' document as extension work throughout the entire project area, supported by credit, and if the credit section had been made subordinate to extension and made to understand that its major role was the provision of subsidised credit, then the existing project organisation would have been in line with its aim. Furthermore, there would have been no doubt as to the roles of the various sections. However, no such categorical statement was made either by the World Bank or by the Project Management Unit, so that the credit section was left to assume that it must make its operation a going concern, without the controls to ensure this happening.

\section{Conclusion}

It is suggested that greater consideration should have been given initially to the relative emphasis between credit and extension. If, as seems to be implied by the lack of any firm statement, the intention was to give equal emphasis to both credit and extension, then consideration should have been given to implementing the organisational recommendations of the Project Preparation Report. These recommendations seem to have been ideally suited to such a situation. Instead, details were given by the 'Grey Cover' document of an organisation which stressed extension by placing Agricultural Officers in charge of the 
regions and separating credit from the field operations.

It is further suggested that, having explicitly chosen a point of emphasis, a suitable organisation design should have been chosen from a number of possible alternatives.

In the lack of attention given at the planning stage to the organisation of activities, the above project is by no means unique, nor was the question of emphasis the only omission during the planning stages. The planning of a project's implementation often seems to be left until the project is actually operating, with the consequent loss of time and effort as well as confusion and misunderstanding. More attention should be paid to planning for implementation. Organisation designs are required which are suitable to specific situations and can identify possible problem areas rather than those that rely on the prescriptive use of traditional concepts such as hierarchy, spans of control and pre-determined managerial roles. 